\title{
Biomedical Waste Management in India: Awareness and Novel Approaches
}

\author{
Anju Singh*1, Seema Unnikrishnan ${ }^{2}$ and Samriddhi Dongre ${ }^{3}$ \\ ${ }^{1,2}$ Environmental Engineering and Management area, National Institute of Industrial Engineering (NITIE), India \\ ${ }^{3}$ Industrial Safety and Environmental Management, NITIE, India
}

Received: 制 January 16, 2019; Published: 制January 25, 2019

*Corresponding author: Anju Singh, Environmental Engineering and Management area, National Institute of Industrial Engineering (NITIE), Mumbai, India

\begin{abstract}
Abbreviations: BMW: Bio-Medical Waste; EPA: Environment Protection Act; HCF: Healthcare Facilities; CBMWTF : Common Biomedical Waste Treatment Facility, CPCB: Central Pollution Control Board; BMW: Biomedical Waste Management; HCF: Health Care Facilities; WHO: World Health Organization; NACO : National Aids Control Organization, MoEF: Ministry of Environment and Forests; SPCB: State Pollution Control Boards; CPCB: Central Pollution Control Board; CBMWTF: Common Biomedical Waste Treatment and Disposal Facility
\end{abstract}

\section{Biomedical Waste in India}

Healthcare is becoming one of India's largest sectors both in terms of revenue and employment and with growing healthcare, there is a requirement of management of Bio-Medical Waste (BMW). Currently, in India, 550.9 tons of Bio-medical waste is generated daily and is likely to reach about 775.5 tons per day by 2022 from the current level [1]. Approximately 75-90\% of the biomedical waste is non-hazardous and as harmless as any other Municipal waste however, the remaining 10-25\%, though mixed with non-hazardous waste, can be injurious to humans or animals as also being detrimental to the environment and needs special handling and treatment due to its highly toxic contents and infectious properties [2].

\section{Risk associated with Biomedical Waste}

The groups of individuals majorly affected by the BMW are the Health care workers, general public and scavengers. BMW increase the exposure to microbial infections, cytotoxic and radioactive elements and chemicals like Mercury, disinfectants and pesticides that affect multi-systems. Improper handling of sharp medical objects like syringes can lead to needle stick injuries which may thereby cause infections with blood-borne pathogens such as HBV, HIV and HCV, etc.

\section{Beginning of Law}

India was one of the first countries in the world to implement Biomedical Waste Management Rules in 1998 under Environment Protection Act (EPA), 1986. These rules provide for the Healthcare
Facilities(HCF) to segregate the biomedical waste as per the 10 categories like Human Anatomical Waste, Animal Waste, Waste Sharps, Liquid and Solid waste etc. into colored bags-yellow, red, blue/white and black according to the category of the biomedical waste [3]. The HCFs can store this waste for up to 48 hours after which they either treat it in-situ or is sent to a Common Biomedical Waste Treatment Facility (CBMWTF). The CMBWTF then treats the waste according to the color of the bag. Different colors call for different types of treatments such as incineration, deep burial, autoclaving, shredding, chemical treatment, disposal in a landfill, etc. If Biomedical waste is to be transported outside the premise where the waste is generated it must carry with itself information like sender's as well as receiver's name and address.

\section{Amendments and Current Status}

Although the Central Pollution Control Board (CPCB) had come up with the 'Bio-medical Waste-Handling and Management Rules-1998' that provided some guidance on how different biomedical waste can be handled, even after a long time of their implementation, most of hospitals in India hadn't adopted the desired standards or a credible Biomedical Waste Management (BMW) system. BMW problem was additionally intensified due the existence of scavengers who deal with open, unprotected health-care waste without any protective equipment like gloves, masks, or shoes for recycling, as also the reuse of syringes without appropriate sterilization. In 2009, about 240 individuals in Gujarat, India had become infected with Hepatitis-B a consequence to 
the reuse of unsterilized syringes [4]. Several studies conducted regularly, depicted that in spite of India being among the first country to initiate measures for safe disposal of BMW, there was an urgent need to take action for strengthening the existing system capacity.

As a result, the BMW, 1998 Rules were modified several times such as in 2000, 2003 and 2011. However, a major improvement was done in the year 2016 with the introduction of new 'Biomedical Waste Management Rules 2016'. The basic contrast between the rules prescribed in 2011 and the new rules was their range of application. Whereas in 2011, the 1998 rules were amended to include all persons who generate, collect, receive, store and transport biomedical waste, the 2016 rules have an increased coverage to include vaccination camps, blood donation camps, surgical camps and all other Health Care Facilities (HCF). The second difference comes in the segregation, packaging, transport and storage of BMW in an HCF. The 2011 draft demarcated eight categories of biomedical waste down from original ten categories in the 1998 notification. The 2016 notification further brings down the number of categories to four to bring about ease of segregation and overcoming the confusion created by the earlier large number of categories. The HCFs have also been made liable for pre-treatment of laboratory and microbiological waste, blood samples and blood bags through disinfection/sterilization on-site which is in accordance with that prescribed by the World Health Organization (WHO) or National Aids Control Organization (NACO), irrespective of whether final treatment and disposal is to happen on-site or at a CBMWTF. Every HCF has been asked to phase out the use of chlorinated plastic bags, gloves and blood bags within two years to eliminate emission of hazardous dioxins and furans released with burning of such wastes.

Further, the new rule also states a bar code system for all bags and containers used for BMW treatment and disposal for better tracking and identification. The 2016 rules also have stricter standards of emission from incinerators with acceptable SPM emissions from $150 \mathrm{mg} / \mathrm{nm} 3$ in 2011 to $50 \mathrm{mg} / \mathrm{nm} 3$ with the new law. While the 2011 rules have no provision for a monitoring authority, the 2016 rules state that the Ministry of Environment and Forests (MoEF) will review HCFs once a year through state health secretaries, the State Pollution Control Boards (SPCB) and the Central Pollution Control Board (CPCB) [5]. Additionally, as per amendments to BMW Rules 2016 (Parent Rule), all the health care facilities irrespective of any number of beds are required to make available the annual report on its web-site stating the information related to Biomedical waste in accordance with Bio-Medical Waste Management (Amendment) Rules, 2018 [6].

\section{Challenges}

One of the biggest challenges posed to the government hospitals and small HCFs, during the implementation of BMW 2016 rules is the availability of sufficient funds to implement the new procedures. To eliminate chlorinated plastic bags, gloves, blood bags and to establish a bar code framework for bags and containers the cost is high and time span of two years to actualize this is greatly restricted [7]. As a result, amendments have been made to BMW Rules 2016 and the date for phasing out them have been extended till 2019 and blood bags have been excluded as per the new BMW Rules 2018. Considering the amount of BMW generated, the number of Common Biomedical Waste Treatment and Disposal Facility (CBMWTF) are limited and there is need of development of more such CBMWTF. 8 states and Union Territories in India are yet to develop CBWTF. Many facilities have not installed ETP / STP for liquid waste disposal as per Schedule II of BMW Rule 2016. Although the acceptable SPM emissions limit from incinerators have been reduced, yet they emit toxic air pollutants, and incinerator ash is potentially hazardous [7].

\section{Greening the Healthcare Sector}

Waste Minimization and Greening of Supply chain in the Healthcare sector can prove to be a major factor in effective management of Biomedical Waste. Environmental information should be integrated into the training and education of the professionals associated with the health care sector to match the changing patterns in ailments and diseases to raise their knowledge of appropriate use and disposal of resources. Considering the complexity of health care waste streams, hospitals and other health care facilities must employ full time Experts to handle waste generated in their respective hospitals and centers so that they can have a lifecycle thinking in their design and purchase standpoints. Waste minimization can be achieved by purchasing reusable items made of glass and metals which can be disinfected and reused [8]. Similarly, using environmentally preferable products can reduce hazardous biomedical waste, like replacing mercury thermometers and Blood pressure gauges with Mercury Free ones. Health care Facilities at various stages can also implement recycling programs by segregating their waste streams for optimal end use as well as material recovery. Finally, appropriate infrastructure needs to be established to in order to have an environmentally conscious management of the biomedical waste.

\section{References}

1. ASSOCHAM India (2018) Unearthing the growth curve and necessities of bio medical waste management in India.

2. Muduli, Barve (2012) Barriers to green practices in health care waste sector: An Indian perspective. International Journal of Environmental Science and Development 3(4): 393-399.

3. Ministry of Environment \& Forests (1998) Biomedical waste management rules.

4. (2009) Times of India, 2009.

5. Government of India Ministry of Environment, Forest and Climate Change (2016) Biomedical waste management rules.

6. Ministry of Environment, Forest and Climate Change (2018) Biomedical waste management rules.

7. P Datta, Mohi GK, Chander J (2018) Biomedical waste management in India: Critical appraisal. Journal of Laboratory Physicians 10(1): 6-14.

8. Muduli K, Barve A (2012) Challenges to waste management practices in Indian health care sector. In International Conference on Environment Science and Engineering. 


\section{ISSN: 2574-1241}

DOI: 10.26717/BJSTR.2019.13.002424

Anju Singh. Biomed J Sci \& Tech Res

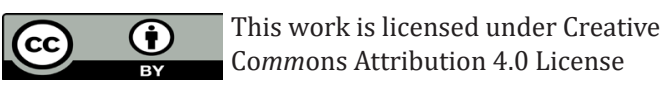

Submission Link: https://biomedres.us/submit-manuscript.php

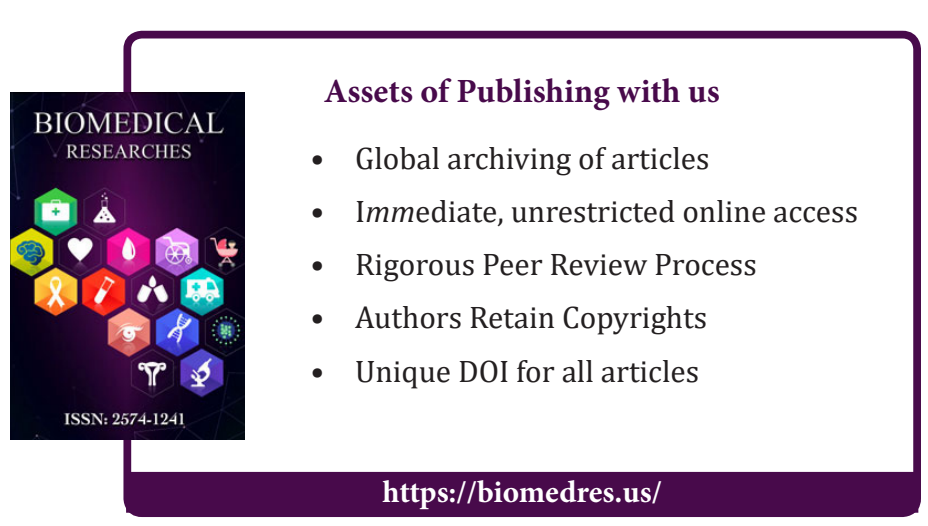

